\title{
On the exploration of the ecology of English language teachers' personal styles in Iran
}

Majid Elahi Shirvan ${ }^{1 *}$, Samira Rahmani ${ }^{2}$ and Laleh Sorayyaee ${ }^{2}$

\author{
* Correspondence: \\ Elahimajid64@gmail.com \\ ${ }^{1}$ University of Bojnord, Bojnord, Iran \\ Full list of author information is \\ available at the end of the article
}

\begin{abstract}
With the shift from a linear predictive perspective to a complex dynamic one in the field of applied linguistics, more ecological studies on English language teachers' behaviors and styles are needed. Thus, the purpose of the present study was to explore Iranian English language teachers' personal styles, namely controlling parent, nurturing parent, adult, adapted child, and natural child, from an ecological perspective. The data collected with 48 semi structured interviews, 96 journals, and 24 observations with 8 English language teachers were analyzed qualitatively by utilizing nested ecosystems model as an analytical framework, which led to the identification of internal and external factors underpinning teachers' personal styles at the micro system. Moreover, the existence of meso, exo, macrosystem and their effects on teachers' personal styles were suggested in the data. The findings of the study indicate that the teachers' constructed personal styles in the classroom are very dynamic and they change within the particularities of each class in terms of the variables explored in this study. More interpretation of systematic intervention of each variable regarding the teachers' personal styles was discussed.
\end{abstract}

Keywords: Teachers' personal style, Ecology of language teaching, Controlling parent, Adapted child, Natural child, Nurturing parent

\section{Introduction}

The term "ecology" was first mentioned by Ernst Haeckel, a German biologist around the middle of the 19th century, referring to the relationship of an organism with all its related organisms (Arndt and Janney 1984). This type of study is contextualized or situated because it considers and studies organisms and their relationship within their environment or ecosystem. It is now considered that humans are a part of a greater natural order or even a great living system (Allen and Hoekstra 1992; Goldsmith 2008; Lovelock 1979). Thus, students, researchers, and teachers' behaviors, beliefs, actions, and styles can be studied from an ecological perspective. Focusing on the fluctuations and diversities of context regarding teachers' development and factors related to the teachers, van Lier (2002)emphasized sevenfactors particular to an ecological study. The first one is affordance whichrefers to the idea that the relationship between an organism (e.g. teacher or student) and its environment can provide the opportunity for

(c) 2016 The Author(s). Open Access This article is distributed under the terms of the Creative Commons Attribution 4.0 International License (http://creativecommons.org/licenses/by/4.0/), which permits unrestricted use, distribution, and reproduction in any medium provided you give appropriate credit to the original author(s) and the source, provide a link to the Creative Commons license, and indicate if changes were made. 
taking action or preventing it. Secondly, context is regarded as the focal part of any ecological research because in this research type, contextual information can be an additional cue surrounding and defining the environment and also being defined by it. The third factor consists of patterns and systems, indicating situations or affairs which are fixed and may not change over time and place. Emergence, as the fourth main feature, refers to the process that different elements or parts of the environment combine or affect each other upon which a new system totally different and also functioning different from its elements emerges. Value, as the fifth factor, means that everything in the environment has the potential to be valuable or value-producing. The sixth feature, diversity, refers to the existence of different individuals or members in a society. The seventh factor refers to the activities of the individual members of the community in every ecosystem.

Recently, the concept of teachers' development has invited lots of attention within different domains such as teachers' belief (Cross 2009; Kulinna et al. 2000; Tondeur et al. 2008; Türel and Johnson 2012), teachers' motivation (Kao et al. 2011; Pelletier et al. 2002), teachers' success (Ghaemi and Taherian 2011; Ghanizadeh and Moafian 2011) and teachers' anxiety (Abu-Rabia* 2004; Beilock et al. 2010; Vinson 2001). However, most of these studies are more empirical and quantitative and have not covered the diversity of factors involved in the construction of these concepts of teachers' development and one of the main ones is teachers' personal styles. Within the current knowledge base, there still remains a lack of concern for an ecological conceptual framework to inform methodology of research on teachers' personal styles. Thus, the need for an ecological conceptual framework underpinning research in teachers' personal styles based on the mentioned ecological factors is felt.

Personal style is known as an ego-state, a psychological factor derived from Transactional Analysis theory of personality and social interaction, as well as a tool used in therapy (Stewart and Joines 1987). It describes how you would think, feel and behave in ways similar to a parent, absorbed in your early years from those who were responsible for your upbringing; similar to a child, you are relying on the thoughts, feelings and behaviors you remember from the years you were a child; or similar to an adult, your thoughts, feelings and behaviors are based on what is happening here and now, rather than on your experiences of long ago. There are two subdivisions of the personal styles of parent and child named controlling parent, nurturing parent, adapted child, and natural child. Totaling up, there are five personal styles; controlling parent, nurturing parent, adult, natural child, and adapted child (Berne 1961).

According to Bronfenbrenner, the context of education is considered as an ecosystem, in which each ecosystem is nested inside the next (Bronfenbrenner 1993, 1994, see Table 1). There are four nested levels in an ecosystem: microsystem, mesosystem, exosystem, and macrosystem ranging from the immediate setting to overarching social and cultural context. Microsystem involves the activities and roles experienced by a developing person such as a teacher in the language classroom. Mesosystem involves the interrelationship between two or more settings that contain the developing person. For instance, the universities or language institutes in which the teacher is developing would be such a system. Exosystem involves the relationship between two or more settings, including at least one in which the developing person is not present, but still receives influence on his/her behavior in the immediate setting, the microsystem. For instance, in establishing the rules of a language 
Table 1 Operationalization of ecosystems and examples of contextual elements

\begin{tabular}{lll}
\hline Level & Operationalization & Examples \\
Micro & $\begin{array}{l}\text { The classroom within which teachers' personal styles } \\
\text { was under study }\end{array}$ & $\begin{array}{l}\text { The teachers' beliefs, attitudes, behavior and } \\
\text { teaching methods used in the classroom }\end{array}$ \\
Meso & $\begin{array}{l}\text { The relationship between the class and other settings } \\
\text { involving the teachers }\end{array}$ & $\begin{array}{l}\text { The teachers' previous experience as a learner } \\
\text { and the lessons they have learned in university }\end{array}$ \\
Exo $\quad \begin{array}{l}\text { The relationship between the class and other settings, } \\
\text { in which the teachers are not involved, but influenced } \\
\text { by in terms of their personal styles }\end{array}$ & $\begin{array}{l}\text { Rules of institution, developing material and } \\
\text { designing a curriculum }\end{array}$ \\
Macro Iran's educational system & $\begin{array}{l}\text { The influence of Iranian cultural heritage on } \\
\text { teachers' personality }\end{array}$ \\
\hline
\end{tabular}

institution, the teacher is not there but receives influence from it. Macrosystem involves the overarching pattern of micro-, meso-, and exosystemsdefined as the characteristics of a given culture, subculture, or other extended social structure. For instance, the educational system in language institutes would call such a system. Thus, the purpose of this study is to take advantage of the potentiality of ecological perspective to shed more light on one specific concept of language teachers' development which is teachers' personal style. That is, the present study explores Iranian English language teachers' personal styles regarding the methods they use in the classroom, their teaching experiences, their age, their gender, and proficiency level of learners. This study aims to answer the following questions;

1- What are the factors influencing Iranian EFL teachers' personal styles?

2- What kind of personal styles do English language teachers prefer in Iran?

3- To what extent does an ecological perspective contribute to understanding teachers' personal styles in the classroom?

\section{Method}

\section{Context and participants}

The present study was conducted in a north eastern city of Iran, Mashhad, over a period of six months, in the academic year of 2014-2015. Participants were eight English language teachers teaching English in language institutes chosen based on convenience sampling. Demographic information of the participants, including age, years of experience, gender, level of students, and teachers' method are presented in Table. 2.

\section{Data collection}

Multiple data were collected through semi-structured interviews, classroom observations, and teachers' journals kept regularly by the participants. Six sessions of semi-structured interviews were conducted individually with each teacher during six months, from December 1, 2014 to June 31, 2015, in which every month an interview was taken from each EFL teacher. Totally 48 interviews were taken. The interview questions are included in Appendix A. The interviews were conducted both in English and Persian and they were recorded, transcribed, and partly translated into English language by the researchers. Besides, the teachers were asked to write two journals every month on their classroom based on the frame work that researchers have provided for them (See appendix B). Totally 96 journals were collected. Furthermore, the second and the third researchers, agreed by the managers of language institutes, observed each teacher's class twice a month. Some special points 
Table 2 Demographic information of case study participants

\begin{tabular}{|c|c|c|c|c|c|c|c|c|}
\hline Case & 1 & 2 & 3 & 4 & 5 & 6 & 7 & 8 \\
\hline Age & 24 & 21 & 30 & 25 & 31 & 28 & 22 & 25 \\
\hline Gender & Male & Female & Male & Female & Female & Female & Male & female \\
\hline Years' of experience & 5 & 2 & 8 & 7 & 9 & 6 & 3 & 5 \\
\hline Students' level & intermediate & Elementary & Advanced & upper intermediate & advanced & Intermediate & Elementary & elementary \\
\hline Teachers' method & CLT & TPR & CLT & ALM & CLT & ALM & TPR & DM \\
\hline
\end{tabular}

Note: CLT Communicative Language Teaching, TPR Total Physical Response, ALM Audio-lingual Approach, DM Direct Method 
were noted in each class by the researchers in each observation (See appendix C). 24 observations were conducted for this study in total.

\section{Data analysis}

Qualitative content analysis was conducted in this study. The data including interviews, journals, and observations were analyzed through reading, coding, and revising the codes. The data, strings of words, sentences, or even paragraphs reflecting a common meaning were coded as one instance. For instance, for a remark like "I shouldn't always be an English teacher, sometimes I had to be a friend, counselor, conductor... as well." two codes were extracted as being the author of the classroom and also being a friend or a counselor to students, to whom they can trust when they need help. This has been done to show the teachers' role as both a controlling parent and a nurturing parent.

Besides, the codes were categorized into different themes emerged inductively from the data. These categories and themes were based on Bronfenbrenner (1993) ecosystems model. However, the focus of this study is the microsystem; the other three ecosystems were explored when their existence was suggested by the data.

\section{Results and discussion}

In the following, findings are presented at four levels based on Bronfenbrenners' nested ecosystem model. At the microsystematic level, nine unfolding codes (sense of humor,students' engagement,different teacher roles, rapportand interaction between the teacher and students, teachers' creativity, students' autonomy, teachers' accessibility, students' appreciation, and reflective teaching) in the classroom setting were identified as influencing teachers' personal styles. They are reported in two strands: (a) internal factors: including cognitive, affective and autonomy factors and (b) external factors: encompassing classroom situation and limitations of institutes. The data also suggested the existence of meso-, exo-, and macrosystemsinfluencing the teachers' personal styles.

\section{A- At the microsystematic level \\ a- Internal factors \\ 1- Cognitive and affective factors}

Cognitive factors concern the techniques and activities that teachers utilize in order to improve students' cognition and metacognition in the classroom. Some data revealed the existence of these factors in the construction of teachers' personal styles such as sense of humor which was a salient feature for teachers. Reflecting on participant 1, onthe use of games and fun in adult classes, we found that he develops and changes his personal style from controlling parent in adult classes to a natural child or a nurturing parent as he noted:

It was during one of my adult classes when I decided to do something fun with the students. They were hesitating over answeringthe question and activities either in pair works or as individuals. So, I took a small ball to play "throw and catch" while doing the activity. First, they seemed so surprised since the class was mixed and it is not customary in Iranian classes of adults to do such a game play. But, the more they got involved in the game, the better they weremaking and responding to questions. By the 
end of the class, everyonewas so excited and eager to play more games during the remaining sessions. Then, it occurred to me that age is not much of a big deal, young or adult, they love to have fun in their class. (Journal 5, December 10, 2014)

In contrast, participant 4 tried not to have any fun in her class because she had some bully students and believed that the use of fun can bring about chaos in her class, so she tended to maintain her controlling parent style, but once she decided to change her personal style to nurturing parent due to an accident in one of her classes. In her journal she wrote:

I would like to write about my interesting yet horrible memory which I have never experienced before. I had a class of all bully male teenagers sometimes terrifying to me, yet I tried to be very strict to show off my power over them. We didn't have any fun moment in class because I didn't even let them smile, otherwise they started to make chaos in class, and get out of control. One day, one of them came late to class and when he entered I made a frown in my face and told him this is the last time you come late or you are kicked out of the class. I showed them how angry I was. (I disclosed my anger) But there I made a mistake, I tried to show my anger towards the incident but I forgot to check out the look on the latecomer's face, after 15 min I understood something is happening in the class, students weren't listening to me teaching anymore, suddenly the latecomer attacked one of his friends. I didn't know what to do at that moment, I tried to separate them but I couldn't and unfortunately one of my students was injured. After that event I understood that this is my fault the latecomer did such a thing, cause if I had treated him kindly and created some humorous situations in the class, this burst of anger and violence would have never happened. So a teacher should never be so strict even with bully students, because this can have a negative effect on them. (Journal 82, June 20, 2015)

Besides, teachers' creativity can contribute to their constructed personal style while addressing the cognition of students. Participant 7 talked about her experience in teaching alphabet;

I was to teach alphabet for the first time to my 5-year-old students. That was very hard on them to become literate in a foreign language. So I tried to be creative in each session for example, Itaught a new lettermaking it with clay, bubbles, papers, pencils..., then we made a story for that letter. Teaching in this way made them so interested in becoming literate. (Interview 32, March25, 2015)

This teacher tried to take on nurturing parent style regarding the students' age in order to engage them creatively in the lesson. Participant 2 expressed her opinion about variety and creativity in the classroom;

Variety is one of the most important things I care about because students care about it. One session I may use internet in the class to explain something. Next time I may ask them to bring a sandwich for fun and talk about sandwiches for an hour in English. The other session I may ask them to talk spontaneously or they might have been prepared for a speech. Sometimes we all play hide and seek in the yard (applied for younger students) and sometimes we discuss the problems students have with each 
other and I always share my own experiences. They kind of enjoy knowing more about their teacher. Something I try to do in all my classes is to work on music and sing with them. They enjoy working on the songs everyday. One of the things I always try for beginners is that they make their own flash cards. Each word they learn, they paint it on a flash card and color it. As the number of the flash cards increase they become so excited about how well they are progressing and it helps them to go on. (Interview 42, June 12, 2015)

As seen in the mentioned interview, this teacher's personal style is dynamic and ranges from a gamut of styles from a natural child, or a nurturing parent to an adapted child in order to add variety to her class.

The contribution of teachers' reflection on their teaching experiences to the construction of their teaching styles was best echoed in the participant 6's remark;

Five years ago when I started my teaching, I decided to handle my classes based on the experiences I have gained from my observations. At the beginning when my students, especially at the elementary levels, misbehaved, I tried to ignore them or accept that their behavior correlates with their age. But after a short time I have found that students should be under control of their teacher no matter how old or proficient they are. From that moment on, I decided to change my style. In other words, after each misbehavior, I tried to reflect on the past and proved them that I'm firm enough to make them face the consequences of their actions so they should watch their behavior. (Interview 9, January 3, 2015)

In this interview, at the beginning the teachers' personal style was adapted child, but gradually as she became more experienced, she changed her personal style to controlling parent. In other words, what she experienced at the mesosystem affected her teaching personal style at the microsystem.

Regarding the issue of reflection on the learners' homework, one teacher has noted that;

Reflecting and commenting on my students' homework is one of the most important steps in my classes. In the first session, I fully explain that the first quarter of each session will be spent on checking the homework they are assigned. I think this is the only way of talking them into doing homework as the most important way to better understanding of the lessons. In addition, in this way my students would come to realize that I'm always there to help them at the time of need, and also I can play an authoritative role in my classes. (Interview 25, March 1, 2015)

As seen in the mentioned interview, the dynamics of the situation shaped the teacher's personal style as both a controlling parent and a nurturing parent to be able to successfully handle his classes. Also, interaction, rapport and sharing information between teachers and students to improve their students' cognition and affection paved the way for their construction of their personal styles in the classroom. In observation 5, January 2, 2015, participant 3 picked up from the story book a scene that was left from the previous session. To follow the plan of implementing extensive reading, he read the story book aloud in a low and comprehensible pace. Interaction carried on 
through a large amount of questions and answers during the reading phase. The reading phase went on several other stages to assure the students' engagement. This indicated that this teacher was very concerned about his students' involvement which turned him into nurturing parent. At the end of the class, his personal style shifted from a nurturing parent to an adapted child in order to assure that students are actively engaged in the story. Different roles teachers played in different situations to improve the students' cognition and affection verified in the data with participant 1 s' report;

I shouldn't always be only an English teacher, sometimes I had to be a friend, a counselor, a conductor... touching their lives, so the duty of a teacher is very heavy however it does not seem to be. (Interview 20, February 12, 2015)

By contrast, participant 8 has neglected the implication of different roles in class;

I had a class of preschool beginners. You know...teaching to preschool learners is very demanding as long as you are not only their English teacher, but also their mom, nurse, dad, friend or peer based on what the situation calls for. It is hard on an English teacher who only knows how to teach English and not to care. (Interview 16, January 24, 2015)

Appreciating and encouraging students also emerged in the data in order to increase students' affection. Two teachers tended to take on adapted child style and sometimes nurturing parent style in their classes in order to appreciate all of the students. They remarked that;

Students should always have something to talk or to write about. I ask them to search on the internet or talk about their own experiences. I do respect them and ask them to share all the time. There were times when my students wanted to talk about their experiences but they were so shy of disclosure. So I asked them to write it down for next session and assured them that I would read them all and tell them my opinion. I try not to disagree with what they say so much but to make them feel I care about what they say. (Interview 8, December 27, 2015)

\section{2- Autonomy factor}

Boosting students' sense of autonomy set the stage for the construction of teachers' personal styles. Participant 5 noted on how she makes students autonomous and independent in her class;

Enhancing students' autonomy, I didn't give my students explicit guidelines or grading rubrics, but rather got them to write their own. As an extension to the activity described above, in which students model the style of a particular journal for their lab reports, I asked my students to write detailed Instructions for Authors as an assignment. In doing so, they must have identified what qualities a good paper should possess on their own. Following the activity, I asked them to use those instructions to write a grading rubric, and then use the grading rubric to grade their own papers. 
Not only did this give them a sense of autonomy, but it helped them develop their self-editing skills. (Journal 55, March16, 2015)

Participant 2 noted that;

That would be wrong if I say I help my students to figure out everything with me by their sides helping them. I try to give them the pleasure of discovering and solving the problems by themselves. But I can't let them be frustrated with that because it saps all their energy and motivation. Sometimes I even fake surprise pretending that they have found something important and tell them how intelligent and good they are at English. It really strengthens their motivation and confidence. This can be a good way to help the lower level students in a class to build up confidence and learn better.

(Interview 12, January 19, 2015)

In the first interview, the teacher constructs an adult style and treats his students as grown-up adults but the second one has shaped a nurturing parent style because she motivates them to be independent in their learning. Engaging students in the lesson appeared to clearly delineate the participants. Two participants engaged students in the lesson dramatically by using creative and amazing techniques applied in the classroom. Participant 1 used driven approach and tried to establish nurturing parent style in order to make her students interested in their learning. Reflecting on the researcher's observation;

She wanted to teach Titanic reading to elementary students of age 9; first of all, she played some parts of the movie and showed them some pictures. As it reads, first she engaged them in the story and raised their interest in reading the story coming very enjoyable to the students. Then she wrote the word Titanic on the board and asked them to reflect on whatever they remembered of the story. This time they were keener on responding correctly and finally they read the story together. (Observation 2,

December 7, 2014)

b- External factors

1- Encompassing classroom situation

Classroom situation has indirectly influenced the situated personal styles of teachers. Here for teachers the classroom situation, which is under the influence of curriculum and the material they are to teach in their class, might not be suitable, so they try to do some modifications in order to tailor the situation for the whole class. The idea was echoed in a participant 5's remark;

Every institute has its own rule. Some give a schedule imposing a particular syllabus to the teachers that exactly reads up to which page they have to teach every session. Other institutes just give the teachers a holistic schedule reading from which and up to which pages they should cover during the semester. I neither followed the first one nor the second one completely. I believe in 'to each its own', meaning different schedules serve 
different attitudes. I can never follow a schedule someone else has planned for me and always give my best shot better off them. I may not teach even one page in a session, however may teach six pages in another. It is different every time and I like this variety in my classes, as does the students. (Interview 6, December 15, 2014)

\section{2- limitation of institutes}

The Most common rules among institutions and schools partly overlapped in the use of L1, methods of teaching, and the appearance. Subsequently, each case is reported. Embracing the use of L1, participant 1 talked about the benefits of L1 while it was forbidden for the institute; The participant, speaking of her experience of childhood, whose teacher had a controlling parent style in the class, developed neither controlling style nor nurturing parent in her class in order not to leave her students with such impression once she was left with. That is, her experiences rooted at the mesosystem affected her construction of personal style at the microsystem.

While teaching, if students do not understand a single word of the teacher's instruction, they will miss the following as well for their mind is obsessed with the one they haven't comprehended. Not everybody has the guts to ask the teacher to repeat his/herself so that they would lose the train! I always make sure whether my students have understood me quite well or not. As soon as I make sure of my students' full understanding, I would move to the next part. Sometimes I can't make it happen without speaking Persian. Reflecting on the time of me learning English, teachers never spoke Persian while teaching complicated grammar rules and because I was the youngest among all the rest I never questioned a thing in fear of judgmental reactions from the teacher or students. All my classes are held sort of bilingual. It is completely against the rule of every institute but I always break this rule. (Interview 36, April 17, 2015)

Participant 8 mentioned his limitation on using the methods prescribed in terms of the rules of the institutes rooted at the exosystem overshadowing the constructed personal style of teachers at the microsystem of the classroom, in this case shifting the teacher from a nurturing parent to a controlling one.

After studying a lot about different teaching methods, and becoming familiar with characteristics of each method, I graduated from university, and won my teaching job. First I tried to put what I have learned out into universe. For example, I knew that according to TPR, students need to have physical movement and fun as much as possible, or according to CLT, foreign language classes should be run communicatively and cooperatively. To my great surprise, after a few sessions of teaching and following procedures of CLT, the supervisor of the institute called me to his office and warned me against applying CLT procedures. After his explanation, I realized that he is after me strictly handling my classes and employing the traditional characteristics of audio-lingual method. So, despite the aspiration of my heart, I have been coerced into changing my teaching style. (Journal 25, January 15, 2015) 
The next limitation is teachers' uniform mentioned by many female teachers, for their appearance is of great importance mostly while teaching to beginners or elementary levels. This point was stated in participant 2's perception of her appearance;

Students always care about how their teacher appears, talks, and moves. They notice how often their teacher tries new clothes. Students of early ages care about how trendy their teacher is. I try to welcome the idea. The first impression is very important to me. And I can't contradict the effect of clothing on it. (Interview 18, February 5, 2015)

This teacher likes to embrace her students' taste in clothes; therefore, thus she constructed the personal style adapted child.

B- At the mesosystematic level

The data also revealed the linkage between the classroom setting and other settings containing the teachers, which can be explored at the mesosystem. This could be found in the fact that teachers' past experiences and what they have learnt in university about teaching might have a significant effect on teachers' constructed personal styles in the microsystem, the immediate teachers' classes. For example, the following comment by participant 2 indicates how her rationale of learning shaped under her learning and teaching background influences the construction of her adapted child or nurturing parent personal style.

Speaking of the major goal of me teaching English, students should enjoy themselves while learning. I know so many people who started English and dropped it. Not so many people attend their classes till the end of the semester. When I was a child I had such problem. I used to hate my teachers and English. But my parents pushed me to pursue my study. Enjoyable learning encourages students to take up the course. I believe that it's my province to help my students and put them in the right track. I am not saying they come to class for fun, but a good teacher is someone who takes advantage of this to teach them and reap benefits. I eat out in the company of my students and talk about best places in the city which offer the best sandwiches. I share songs, movies and clips with them and chat about famous singers, stars, new albums and so on. All of these activities are controlled serving a particular purpose. They learn, enjoy, and hardly wait for the next session to come. (Interview 15, January 7, 2015)

The same can be true about participant 7's situated personal style. Her ontogenetic development, under the influence of his university courses about teaching methods made him tailor his personal styles to the well-grounded theories underlying those methodologies. He stated:

When I was a university student, I studied different teaching methodologies. On the word of TPR, the teacher in a class of children should try to behave as childlike and active as possible. Consistent with what I have studied, when I started my job as a teacher of elementary levels, I tried to behave like children doing my best to present lessons through games. (Journal 66, April 4, 2015) 
Similarly, participant 2 was under the impression of unpleasant background from which she was drawn for her unfriendly strict teacher who had established controlling parent style. But she decided not to let a faulty memory haunt her students, so she took on nurturing parent and adapted child style. She noted that;

I always reflect on the time when I was a student of English (I started learning English when I was 8) which was so hard on me for teachers never intimating students into mysteries of learning-oriented interactions. They just taught us something with hard language and left us with difficult grammatical homework which is not true for me. After a few sessions of my classes held, I handed my students my cell phone number in case of them having problems or questions to put. Then I am available all the time." (Journal 73, April 15, 2015)

Regarding the adaptation of different personal styles to different teaching situations, two effective sources might contradict each other at the mesosystem level. Despite teachers' awareness of the underlying principles of humanistic approaches, due to the immediate needs of the class, they might develop different personal styles as observed in participant 1's switch in his personal style from a nurturing parent to a controlling parent.

Although I have become familiar with different teaching methodologies, sometimes they are not really applicable to real situations. I know that the teachers' behavior and teaching style should serve the learners' needs as in humanistic approaches, because in some classes, especially of male students, students should be strictly controlled and I should play an authoritative role; otherwise, I would not be able to be in control of them and handle my class. (Interview 14, January 23, 2015)

\section{C-At the exosystematic level}

The bond among the classroom setting, curriculum design, institutional rules, and material development in the construction of teachers' personal styles can be explored at the exosystem. As mentioned by some participants, the course syllabus, curriculum, and institutional rules might be in some cases overshadow their background experiences and knowledge derived from university courses. They mostly referred to the use of L1, methods of teaching, and the appearance. Following, each case is reported;

On behalf of using L1 in class, participant 7 pointed out that using L1 is of considerable benefit although it was forbidden;

While teaching, when students do not understand one part they miss the following lessons and their mind is obsessed with it. Not everybody can ask the teacher to repeat again and they might lose the train! I always make sure they understand me quite well and I move to the next part. I can't make sure that it happens all the time but because of the bad experiences I had when I was a child (teachers never spoke Persian when I was a student. They continued teaching complex grammar rules in English and since I was the youngest in class I could never ask question. I was afraid 
of being shown as a stupid kid) I try to explain in Persian too. All my classes are sort of bilingual. It is completely against the rule of every institute but I always break this rule. (Interview 30, March 30, 2015)

This teachers' unpleasant experience as a student having a teacher with a controlling parent style who was following the rules of the institute in terms of not using L1 in the class, and not being able to follow the course made her construct a nurturing parent style and ignore rules like "Do not Use Persian in the Class".

Participant 4 noted about his limitation on using methods;

After studying a lot about different teaching methods and becoming familiar with characteristics of each method and graduating from university, I have started my job as a teacher. First, I have tried to apply what I have learned in my classes. For example, I knew that according to TPR, students need to have more activity and fun as much as possible or according to CLT, foreign language classes should be as communicative as possible and students should interact with each other. But after a few sessions of teaching and following rules of CLT, the supervisor of the institute called me to his room and warned me of not teaching in this way and to change my teaching style. After his explanation, I found that he wanted me to strictly handle my classes and apply the traditional characteristics of audio-lingual method. So, despite my willing, I was forced to change my teaching style. (Journal 2, December 2, 2014)

Similarly, the regulations of the institute were imposed on the teacher, forcing him to behave differently, constructing a controlling parent style in the class.

The regulations established by the institutes on the appearance of the teachers, mainly mentioned by many English female teachers, were the next limitation. This point was observed in participant 7's perception of her appearance;

In our institute, we had lots of rules to follow but some of them intervene in my teaching, such as the way I dress at work. I would like to have a good appearance wearing light clothes, but I wasn't permitted. So I think this would definitely set my students' mind as English teacher tend to wear dark clothes with the result that the elementary and beginner students and teachers would be demotivated. (Interview 24, February 30, 2015)

This teacher tends to adopt nurturing parent style in her class although the rules of the institutes do not allow such a style running, and make her develop controlling parent style instead.

The curriculum, syllabus, and material of the classroom also appeared to be influential in the study as some teachers prefer to form nurturing parent style because they care about what they teach. For this purpose, to accomplish, they might develop another material or curriculum for their classes, despite their having ready material and curriculum. So here the situation in which the teachers are, does not gratify their desire but make them come to their senses and establish the idea of a fundamental change and put it into practice.

Participant 8 used a different strategy in her class and commented that; 
I had a class of lazy students not studying their book, whenever I came to class and asked the meaning of some words, they only passed me a smile. After that on I decided to push them some way else. It occurred to me that it's a good idea to make a picture dictionary with students to get them enjoy learning new words. Later on my students were really hungry to learn more. (Journal 48, February 28, 2015)

The more experience she gained, the more understanding of teaching she processed in terms of varied classes. Here it seems that the teacher first had an adapted child style which later on switched to nurturing parent style, learning from her salutary experience occurring at the mesosystem level, in order to facilitate learning in her class. However, there were two participants who seemed to have violated the rule of the institute to work up an appropriate class schedule. Participant 3 pointed that;

Once I started to teach in a new institute, they obliged me to follow their already developed curriculum and materials. Since it came to my notice from the very beginning moment of applying them in my class that they won't work, I carried out some curriculum modifications in order to make them go with my class. However, I met with unpleasant consequences for I closed my eyes tothe rules of the institution. (Journal 71, April 21, 2015)

In the similar vein, participant 5 said;

Every institute has its own rule. Some gave a schedule which forced teachers to which page they need to teach. They exactly wrote the number of pages needs to be taught in every session. Other institutes just give a whole schedule that says where to start and where to finish in a term. I never obeyed the first one nor the second one completely. I think each class is unique. It requires different schedules and different attitudes. I can never obey a schedule others planned for my class. In addition, I always do the best without obeying them. I may not teach even one page in a session and may teach six pages in other. It is different every time and I like this variety in my classes, as do the students. (Interview 47, June 29, 2015)

Since the particularity of classes and students are very important to these two teachers, they tried their best to create a favorable situation to the students and did some curriculum adjusting to teaching classes of different needs and airs, thus their personal style turned to be adapted child. So here the rules of institutes, rooted at the exo-system and the teachers' sense of plausibility, shaped at the mesosystem are in contrast with each other, meaning that the rules of institutes tends to regulate the construction of teachers' personal style, but teachers attempt to remove this trend by constructing their own situated personal style.

\section{D- At the macrosystematic level}

The macrosystem was viewed to be consisted of educational system, and cultural factors influencing the microsystem. The Iranian cultural heritage brought about a considerable effect on teachers' personal styles. Iran's past culture was more of a teachercentered revealed in a scenario between participant 4 and a student observed by the researcher; 
The scenario(observation 13, March 14, 2015)

Teacher: today all of you have to copy down this passage 5 times!

Student: but why?! We are so busy...

Teacher: under my roof, under my rule, clear?!

Student: (silence in $5 \mathrm{~s}$ )

As the teacher's authoritative way of speaking implies, he has established controlling parent style. He is still a firm believer in the effectiveness of bygone authoritative teaching style ordering students around. Former teaching environment has been widely echoed with the culture of authority or authoritative attitude gradually fading away through learner empowerment. Participant 3 stated;

I believe that students' reaching sense of flow is a product of student empowerment in classroom environment. So as a teacher sometimes I embolden my students through group work activities and some other entertaining activities. (Interview 23, February 24, 2015).

\section{Conclusion}

Utilizing Bronfenbrenner's ecosystem framework, this study provides contextualized understanding of teachers' personal styles in EFL classrooms in the context of Iran. Realizing that teachers' personal style is under the impression of a range of systems, we can institute a fruitful major change in educational system. The current findings indicate that the emergence of teachers' personal style in the EFL classrooms was ecologically influenced by a range of internal and external factors. The cognitive, affective, and motivation factors were considered as internal factors and limitations of institutions and classroom situation involving curriculum and material development were assumed as external factors. Internal and external factors underpinning teachers' personal styles were explained at the four levels of nested ecosystem model. Internal factors could make a direct impact on micro- and mesosystems and, as a consequence, indirectly affect exo- and macrosytems. For instance, motivation factor may account for enormous variation in EFL teachers' personal styles, as Dörnyei noted if teachers are motivated themselves, they can motivate learners, too (Dörnyei and Kubanyiova 2014). Thus, if the teacher, at the microsystem of the classroom, changes his/her personal styles consistent with the students' needs and the classroom environment, she/he can stimulate the learners, too which can exert a ripple effect on the other dimensions of the ecosystem as well. On the other hand, when it comes to the external factors, for instance, a fundamental change of institutional rules can make a beneficial effect on the other systems influencing the emergence of teachers' personal styles.

\section{Limitation of the study}

Coming across the limitations of the study, first off, this study has been performed on a small number of participants. Thus, no doubt, to put the particular outcomes out in the universe, data should be delivered by a larger sample of students in a longer passage of time. Clear about this limitation, acted on a relatively straightforward and commonsense methodology according with the ecological principles, we hope this piece can bring insight to the silent under-looked dynamic processes in systems contributing to the emerging patterns of English language teachers' personal styles as long as the 
previous methodologies were often poor layers. Moreover, the present article has no intension providing an all-inclusive scrutiny of all these patterns and systems, but is to represent a more enhanced version of students' real-time behavior. Besides, describing the dynamics of the construction of teachers' personal styles in the class in terms of its underlying ecology seems rather complex. To do so, this study utilized an individuallevel analysis. Therefore, significance testing is of no concern but rather triangulating qualitative data is made bold. The stronger these relationships come to chain up among the different drivers of data, the more trustworthy the inferences are being made.

\section{Appendix A}

Interview questions

1- How many years have you been teaching English?

2- Talk about your past experiences of language learning.

3- Explain any situation that made you change your personal style.

4- How is your relationship with the students in your class?

5- Talk about the atmosphere of your class.

6- What are the rules of institution?

7- What methods do you use in your class?

8- What did you learn at university about teaching?

\section{Appendix B}

Journal framework

1- How was your relationship with students?

2- Did you choose appropriate personal styles in your class?

3- During 90 min period of your class, when did you feel to change your personal style?

4- What was the classroom atmosphere like in your class today?

5- Is there anything which prevents you to use your favorite personal style in class?

6- Generally, how did you feel about your personal style inside today's class?

\section{Appendix C}

\section{Classroom observation criteria}

1- The method of the teacher

2- The personal style of teacher in different situations

3- The relationship between the teacher and the students

4- The atmosphere in the classroom

Authors' contributions

All the authors of this study including ME, SR, and LS have contributed to the collection, analysis, and interpretation of data and also drafting the manuscript and its final revision. All authors read and approved the final manuscript.

Competing interests

The authors declare that they have no competing interests. 
Received: 28 May 2016 Accepted: 12 September 2016

Published online: 10 October 2016

\section{References}

Abu-Rabia, S. (2004). Teachers' role, learners' gender differences, and FL anxiety among seventh-grade students studying english as a FL. Educational Psychology, 24(5), 711-721.

Allen, T., \& Hoekstra, T. W. (1992). Toward a unified ecology. New York: Columbia University Press.

Arndt, H., \& Janney, R. W. (1984). The duck-rabbit phenomenon: Notes on the disambiguation of ambiguous utterances. In W. Enninger \& L. M. Haynes (Eds.), Studies in language ecology (pp. 94-115). Wiesbaden: Franz Steiner Verlag.

Beilock, S. L., Gunderson, E. A., Ramirez, G., \& Levine, S. C. (2010). Female teachers' math anxiety affects girls' math achievement. Proceedings of the National Academy of Sciences, 107(5), 1860-1863.

Berne, E. (1961). Transactional analysis in psychotherapy: A systematic individual and social psychiatry. New York: Grove.

Bronfenbrenner, U. (1993). The ecology of cognitive development: Research models and fugitive findings. Development in context: Acting and thinking in specific enviroments, 3-44.

Bronfenbrenner, U. (1994). Ecological models of human development. Readings on the development of children, 2, 37-43.

Cross, D. I. (2009). Alignment, cohesion, and change: Examining mathematics teachers' belief structures and their influence on instructional practices. Journal of Mathematics Teacher Education, 12(5), 325-346.

Dörnyei, Z., \& Kubanyiova, M. (2014). Motivating learners, motivating teachers. Cambridge: Cambridge University Press. Ghaemi, H., \& Taherian, R. (2011). The role of critical thinking in EFL teachers' teaching success. MJAL, 3(1), 8-22.

Ghanizadeh, A., \& Moafian, F. (2011). The relationship between Iranian EFL teachers' sense of self-efficacy and their pedagogical success in Language Institutes. Asian EFL Journal, 13(2), 249-272.

Goldsmith, E. (2008). The way: An ecological world-view. Athens: University of Georgia Press.

Kao, C.-P., Wu, Y.-T., \& Tsai, C.-C. (2011). Elementary school teachers' motivation toward web-based professional development, and the relationship with Internet self-efficacy and belief about web-based learning. Teaching and Teacher Education, 27(2), 406-415.

Kulinna, P. H., Silverman, S., \& Keating, X. D. (2000). Relationship between teachers' belief systems and actions toward teaching physical activity and fitness. Journal of Teaching in Physical Education, 19(2), 206-221.

Lovelock, J. E. (1979). Gaia, a new look at earth. London: Oxford University Press.

Pelletier, L. G., Séguin-Lévesque, C., \& Legault, L. (2002). Pressure from above and pressure from below as determinants of teachers' motivation and teaching behaviors. Journal of Educational Psychology, 94(1), 186.

Stewart, I., \& Joines, V. (1987). TA today: A new introduction to transactional analysis. Nottingham: Lifespace Publishing.

Tondeur, J., Hermans, R., van Braak, J., \& Valcke, M. (2008). Exploring the link between teachers' educational belief profiles and different types of computer use in the classroom. Computers in Human Behavior, 24(6), 2541-2553.

Türel, Y. K., \& Johnson, T. E. (2012). Teachers' belief and use of interactive whiteboards for teaching and learning. Journal of Educational Technology \& Society, 15(1), 381-394.

Van Lier, L. (2002). An ecological-semiotic perspective on language and linguistics. Language acquisition and language socialization: Ecological perspectives, 140-164.

Vinson, B. M. (2001). A comparison of preservice teachers' mathematics anxiety before and after a methods class emphasizing manipulatives. Early Childhood Education Journal, 29(2), 89-94.

\section{Submit your manuscript to a SpringerOpen ${ }^{\circ}$ journal and benefit from:}

- Convenient online submission

- Rigorous peer review

- Immediate publication on acceptance

- Open access: articles freely available online

- High visibility within the field

- Retaining the copyright to your article 